\title{
Assessment of Patient Safety Culture among Healthcare Providers
}

\author{
Hilal H. Alrahbi ${ }^{1}$, Shamsa K. Al-Toqi ${ }^{2}$, Sajini Sony ${ }^{2} \&$ Nuha Al-Abri ${ }^{2}$ \\ ${ }^{1}$ Department of Research, Diwan of Royal Court Medical Services, Muscat, Oman \\ ${ }^{2}$ Department of Studies and Quality Assurance, Diwan of Royal Court Medical Services. Muscat, Oman \\ Correspondence: Hilal H. Alrahbi, BSN. MSN. PhD, Diwan of Royal Court Medical Services, P.O. Box 343, \\ Postal Code 111. Muscat, Oman. Tel: 968-99-844-108.
}

Received: November 12, 2020 Accepted: December 8, 2020 Online Published: December 23, 2020

doi:10.5539/gjhs.v13n2p59 URL: https://doi.org/10.5539/gjhs.v13n2p59

\begin{abstract}
Purpose: Patient safety is an important element in ensuring quality of patient care and accreditation. This study aimed to assess the perception of patient safety culture among the healthcare providers; assess the areas of strength and improvement related to patient safety culture; and assess the relationship between patient safety culture and demographic variables of the sample.
\end{abstract}

Method: Descriptive correlational design was employed in this study. Data was collected using the Hospital Survey on Patient Safety Culture (HSPSC). A stratified random sample of 158 healthcare providers from the Diwan of Royal Court Health Complex in Muscat participated in this study.

Results: The findings of this study indicated that most of the participants responded positively to the HSPSC items. The average percentage of positive responses was $56.4 \%$. The major areas of strength were "teamwork within department," "feedback and communication about errors," and "organizational learning-continuous improvement" (83\%, 77\%, \& 75\%; respectively). The major areas of improvement were "frequency of events reported," "teamwork across departments," "non-punitive response to errors" and "overall perception of PS" (34\%, 42\%, 45\% \& 47\%; respectively). Significant differences found were across "patient contact" characteristic $[t(156)=2.142, p=.034]$; across "work specializations" $[F(3,154)=2.84, p=.04]$; and across "years of experience at the institution" $[F(4,153)=4.86, p=.004]$.

Conclusion: A culture that is safe for healthcare providers to work is paramount to minimize adverse events and save patients' lives. The findings of this study provide a foundation for further interventions to improve patient safety culture.

Keywords: patient safety, healthcare providers, safety culture, Oman

\section{Introduction}

Patient safety (PS) is a crucial issue concerns healthcare organizations at different levels. It is a multifaceted issue that entails comprehensive, collaborative, and multidisciplinary efforts. In its essence, PS is about preserving the basic fundamental goal of healthcare institutions which is providing quality of care that is error-free and curative (Agency for Healthcare Quality and Research [AHQR], 2019; Institute of Medicine [IOM], 2004). Adverse events in healthcare threaten PS and are one of 10 leading causes of death and disability in the world. It is estimated that at least one in every 10 patients is harmed while receiving healthcare, accounting for about 2.6 million deaths annually due to unsafe care (World Health Organization [WHO], (2019). In high-income countries, about 15\% of hospital expenditure is spent in treating patients affected by unsafe care such as medication errors (Slawomirski, Auraaen, Klazinga, 2017). About 50\% of most hospital adverse events are preventable because they are operation-related rather than lack of human performance (de Vries, Ramrattan, Smorenburg, Gouma, \& Boermeester, 2008).

The complexity of healthcare systems coupled with scarce resources creates a culture plausible for unsafe care. Ensuring a culture that is safe to practice saves lives, resources, and indicates organization commitment toward providing quality of care (AHQR, 2016; Berry et al., 2020). Patients' safety is also a key component in accreditation of healthcare organizations, signifying integrity and fulfillment of their obligations. The Joint Commission of Healthcare Organizations defines safety culture as "the product of individual and group beliefs, values, attitudes, perceptions, competencies, and patterns of behavior that determine the organizations 
commitment to quality and patient safety" (The Joint Commission of Healthcare Organization [JCHO], 2017).

Organizations preserving a positive PS culture function based on mutual trust, open communication, teamwork, and support for workforce (Donaldson, Corrigan, \& Kohn, 2000; El-Jardali, Jaafar, Dimassi, Jamal, \& Hamdan, 2010). The Institute of Medicine (IOM) emphasizes that "the biggest challenge to moving toward a safer health system is changing the culture from one of blaming individuals for errors to one in which errors are treated not as personal failures, but as opportunities to improve the system and prevent harm (Donaldson, Corrigan, \& Kohn, 2000). Developing a culture of safety is paramount for healthcare organizations, and requires multidisciplinary efforts. Healthcare providers are the key in such efforts because their perceptions, beliefs, and attitudes about safe culture determine the degree toward embracing safe practices while executing their roles (Chen \& Li, 2010; Neiva $\&$ Sorra, 2003).

Assessing PS culture within healthcare organizations is the first step in establishing such culture and moving forward to quality of care. Globally, plethora of research were conducted to assess PS culture from different dimensions. The most studied dimensions of PS culture are teamwork, communication, feedback about error, events reporting, organizational learning, non-punitive response to error, management support, staffing, and supervisor expectations and actions, (Waterson, Carman, Manser, \& Hammer, 2019). For example, a national survey of 23,781 healthcare providers in Sweden indicated that the highest rated dimensions of PS culture were "teamwork within units" (73.5\%) and "non-punitive response to error" $(67.2 \%)$, whereas the lowest rated dimensions were "management support for PS" (48\%) and "staffing" (52\%) (Danielsson, Nilsen, Rutberg, \& Årestedt, 2019).

Although limited, studies (Al-Mandhari et al., 2014; Al Nadabi, Faisal, \& Mohammed, 2020; Ammouri, Tailakh, Muliira, Geethakrishnan, \& Al Kindi, 2015; Lawati, Short, Abdulhadi, Panchatcharam, \& Dennis, 2019) conducted in Oman in the area of PS culture uphold the necessity to assess PS culture as an initial step toward creating a culture conducive to safe practice, and subsequently, improving the quality of care of the Omani people. To meet the national and international standards for quality and PS, the Directorate General of Quality Assurance Center (DGQAC) was established by the MOH. The DGQAC affirms the need for an ongoing assessment of PS to improve the quality of care in Oman. The DGQAC initiated different PS projects such as "establishing healthcare quality and PS pillars" and "PS friendly hospital initiative" (Ministry of Health $[\mathrm{MOH}], 2015$ ). One of the first empirical studies to assess PS culture in Oman was conducted in 2014 (Al-Mandhari et al., 2014). The study employed the Hospital Survey for Patient Safety Culture (HSPSC) to measure PS culture, and included a random sample of 390 healthcare providers from 5 regional hospitals. The results indicated that the overall average positive perception toward PS culture was $58 \%$. The researchers report that this average was comparable to the averages of the USA, Taiwan, and Lebanon $(p>0.05)$. Further, "organizational learning" and "continuous improvement" dimensions of PS culture were the highest rated responses, while "non-punitive response to errors" was the least rated by the participants.

As indicated previously, assessing PS culture of healthcare organizations is the first critical step in the process of creating and assuring safe working culture, and consequently, impacting the quality of care of patients. To this end, this study aimed to assess the perception of PS culture among the healthcare providers of the Diwan of Royal Court Health Complex (DRCHC) in Muscat; assess the areas of strength and/or improvement that are related to PS culture; and assess the relationship between PS culture and demographic variables of the sample. The results of this study will provide baseline knowledge that is important in establishing future interventions to improving PS culture and quality of care.

\section{Method}

\subsection{Characteristics of Study Setting and Sample}

This study was conducted at the DRCHC, Muscat. This institution, predominantly, provides primary healthcare to many government employees and their families, particularly those working at the Diwan of Royal Court (DRC). It has about 670 employees. Sample size was determined by power analysis using Raosoft sample size calculator (Rassoft, 2004). At 90\% level of confidence and 5\% margin of error, a minimum sample of 176 was needed for this study. A stratified random sample of 158 respondents participated in this study. Participants were included if they were medical or paramedical staff of the DRCHC; with at least one year of working experience at this institution; provide direct or indirect patient care/service; and read English.

\subsection{Design}

This study employed a descriptive correlational design. 


\subsection{Measurements and Data Collection Procedure}

Subjects who meet the inclusion and exclusion criteria were approached during the working hours, explained the purpose of the study, and invited to participate in the study. Data was collected by 2 of the researchers using the Hospital Survey on Patient Safety Culture (HSPSC). HSPSC is a likert-type scale and includes 42 items that measure 12 areas or composites of PS culture. These areas are mentioned in Table 2. Handoffs and transitions composite were not used in this study because the setting is a primary healthcare institution with no admission beds in which handoffs is not frequently practiced. Hence, 11 composites remained in the study represented by 38 items, with a minimum score of 38 and a maximum score of 190. Higher scores on the overall survey and on each composite indicate positive PS culture, whereas lower scores indicate negative PS culture. The HSPSC was developed by the Agency for Healthcare Research and Quality in which composite scores were calculated by averaging the percent positive responses on the items within a composite (Sorra et al., 2016). Previous research using the HSPSC tool within the USA and cross-culture (Ammouri, Tailakh, Muliira, Geethakrishnan, \& Al Kindi, 2015; Danielsson, Nilsen, Rutberg, \& Årestedt, 2019; El-Jardali, Jaafar, Dimassi, Jamal, \& Hamdan, 2010; Sorra \& Dyer, 2010) indicated acceptable internal consistency reliability $(\geq 0.7)$.

\subsection{Ethical Consideration}

Approval was obtained from the Research Ethics Committee (REC) of the Directorate General of Medical Services, Diwan of Royal Court (REC/883/2018). Voluntary written informed consent was obtained.

\section{Results}

\subsection{Characteristics of the Sample}

The target sample of this study was 176. Two hundreds questionnaires were distributed for those who met the inclusion and exclusion criteria. A total of 160 questionnaires received back, of which 2 were excluded for errors and incompletion, constituting a response rate of $79 \%$. Most of the participants were paramedical (38\%), and most of them (68\%) have been working in in the institution for more than 20 years. The majority $(86.7 \%)$ have contact with patients (direct patient care or interaction) (Table 1).

Table 1. Demographic Characteristics of the sample $(\mathrm{N}=158)$

\begin{tabular}{|c|c|c|c|}
\hline Variable & & $\mathbf{N}$ & $\%$ \\
\hline \multicolumn{4}{|c|}{ Work/unit/specialty } \\
\hline & Doctors* & 38 & 24.1 \\
\hline & Nurse & 52 & 32.9 \\
\hline & Paramedical** & 60 & 38 \\
\hline & Medical assistance & 8 & 5.1 \\
\hline \multicolumn{4}{|c|}{ Overall experience (years) } \\
\hline & $<1$ & 0 & 0 \\
\hline & $1-5$ & 13 & 8.2 \\
\hline & $6-10$ & 30 & 19 \\
\hline & $11-15$ & 3 & 1.9 \\
\hline & $16-20$ & 5 & 3.2 \\
\hline & $\geq 21$ & 107 & 67.7 \\
\hline \multicolumn{4}{|c|}{ Experience in current department (years) } \\
\hline & $<1$ & 0 & 0 \\
\hline & $1-5$ & 16 & 10.1 \\
\hline & $6-10$ & 29 & 18.4 \\
\hline & $11-15$ & 5 & 3.2 \\
\hline & $16-20$ & 9 & 5.7 \\
\hline & $\geq 21$ & 99 & 62.7 \\
\hline
\end{tabular}




\begin{tabular}{llll} 
Working hours per week & & & \\
& $20-39$ & 132 & 83.5 \\
& $40-59$ & 20 & 12.7 \\
& $80-99$ & 5 & 0.6 \\
& $\geq 100$ & & 3.2 \\
\hline Contact with patients & & 137 & 86.7 \\
& Direct & 21 & 13.3 \\
\hline
\end{tabular}

*doctors: physician/Dentist/radiologists

**paramedical: radiographers, physiotherapists, lab. Tech, pharmacists.

Data from the 158 participants were used to test the internal consistency reliability of the HSPSC scale and sub-scales using Cronbach's alpha (Cronbach, 1951). The Cronbach's alpha coefficient for the HSPSC was .89, which exceeded the acceptable value of .70, indicating high internal consistency reliability. Cronbach's alpha coefficient on most of the sub-scales of the HSPSC also indicated high reliability (Table 2).

Table 2. Cronbach'Alpha Coefficient for the HSPSC Scale and Sub-Scales $(N=158)$

\begin{tabular}{lll}
\hline HSPSC and Composites & No. of items & Cronbach's \\
\hline Hospital Survey of Patient Safety Culture (HSPSC) & 38 & .89 \\
Teamwork within units/departments/sections & 4 & .85 \\
Teamwork across units/departments/sections & 4 & .71 \\
Communication openness & 3 & .71 \\
Feedback and communication about error & 3 & .76 \\
Frequency of events reported & 3 & .85 \\
Organizational learning & 3 & .82 \\
Non-punitive response to error & 3 & .79 \\
Management support for PS & 3 & .55 \\
Staffing & 4 & .41 \\
Supervisor/manager expectations and actions & 4 & .48 \\
Overall perceptions of PS & 4 & .33 \\
\hline
\end{tabular}

\subsection{Overall level of PS Culture}

The findings of this study indicated that most of the participants responded positively to the HSPSC items. The average percentage of positive responses was $56.4 \%$ (Figure 1). The mean value of HSPSC scores was 130 and the standard deviation was 18 (Table 3). Higher scores $(\geq 145)$ on the HSPSC were achieved by $20 \%$ of the participants. The majority of the participants $(73 \%)$ scored $\geq 110$ on the HSPSC. Only $5 \%$ of the participants scored $<100$ (Figure 2). 


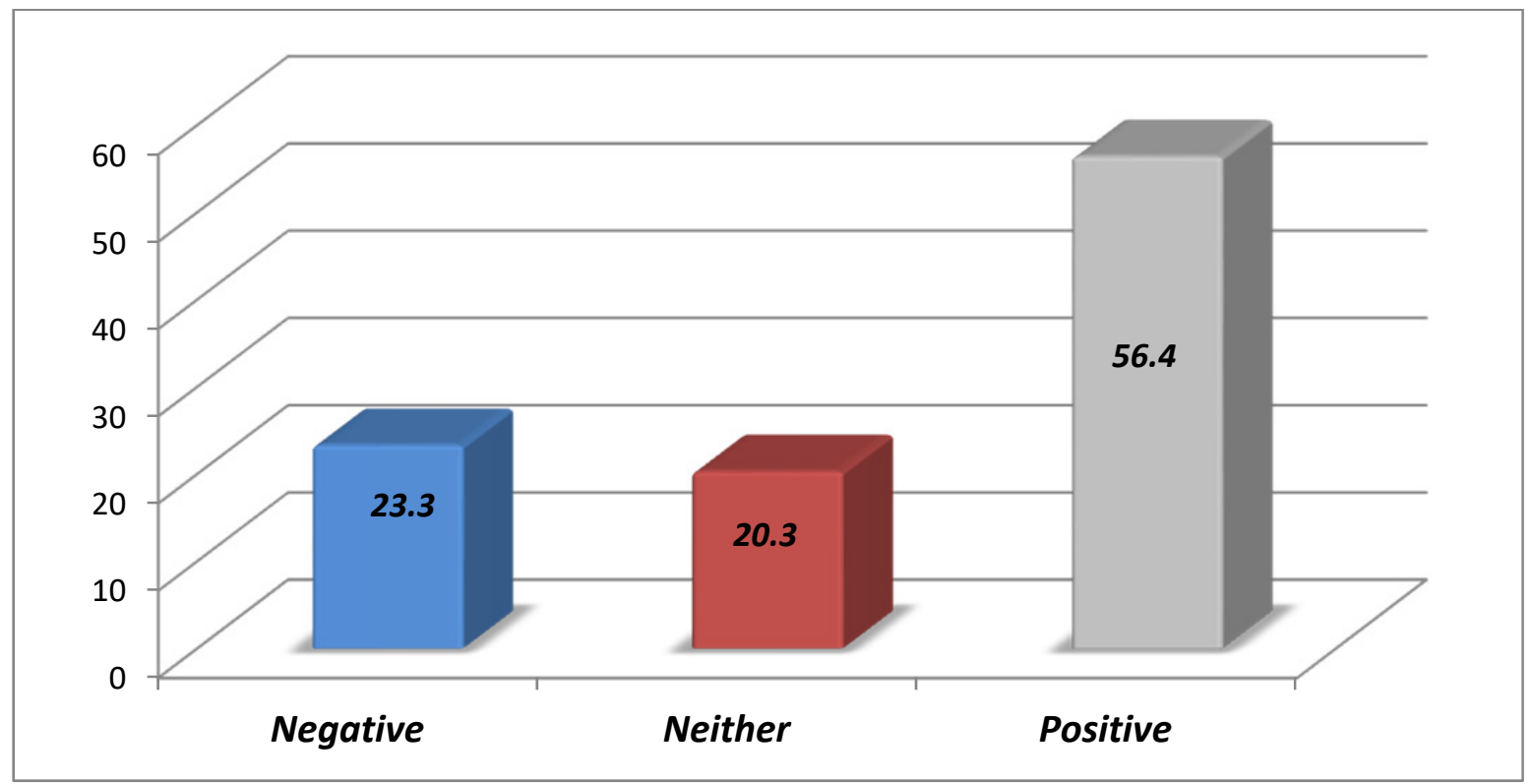

Figure 1. Average percentage of responses of PS culture $(\mathrm{N}=158)$

Table 3. Statistics of HSPSC Scores $(\mathrm{N}=158)$

\begin{tabular}{ll}
\hline Mean & 130 \\
Median & 130 \\
Mode & 131 \\
Std. Deviation & 18 \\
Minimum & 76 \\
Maximum & 186 \\
\hline
\end{tabular}

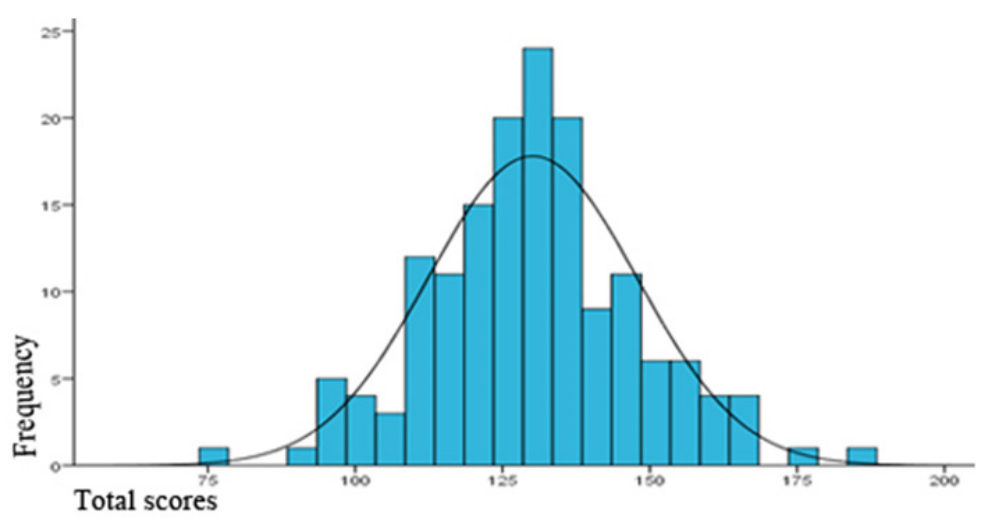

Figure 2. Scores on the HSPSC scale $(\mathrm{N}=158)$

\subsection{Levels of Each Composite of PS Culture}

Scores on each composites of patients' safety culture showed different results. Composite scores $\geq 75 \%$ of positive responses were considered area of strength, whereas composite scores $\leq 50 \%$ of positive responses were considered area of improvement (Sorra et al,. 2016). The major areas of strength were "teamwork within department," "feedback and communication about errors," and "organizational learning-continuous improvement" $(83 \%, 77 \%$, \& 75\%; respectively). The major areas of improvement were "frequency of events reported," "teamwork across departments," "non-punitive response to errors" and "overall perception of PS" (34\%, 42\%, 
45\% \& 47\%; respectively) (Figure 3).

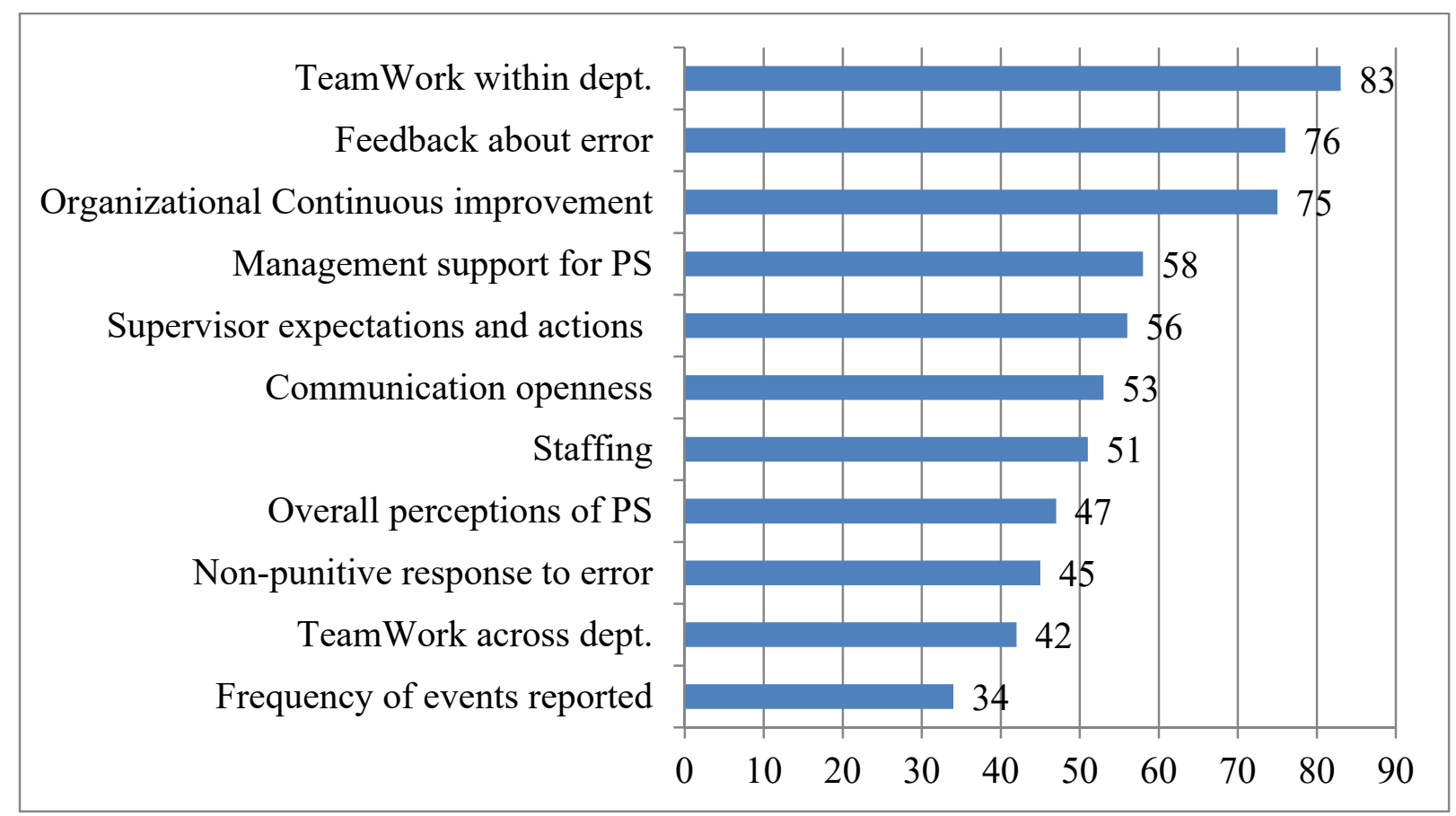

Figure 3. Percentage of positive responses of each composite of PS culture $(\mathrm{N}=158)$

\subsection{Relationship between Overall HSPSC Scores and Demographic Characteristics}

The findings indicated that the overall HSPSC scores differ only across two demographic characteristics. Significant differences found were across "patient contact" characteristic $[t(156)=2.142, p=.034]$, in which participants with direct patient contact scored significantly higher $(\mathrm{M}=131, \mathrm{SD}=18)$ on overall HSPSC compared to those with no or less patient contact $(\mathrm{M}=122, \mathrm{SD}=12)$. Further, the overall HSPSC scores was significantly different across the years of experience in the institution $[F(4,153)=2.451, p=.048]$. Post hoc comparisons using Tukey's LSD test showed that healthcare providers with $\leq 5$ years of work experience scored higher on the HSPSC than those with $>5$ years of experience.

\subsection{Relationship between Each HSPSC Composite Scores and Demographic Characteristics}

The findings indicated that there were significant differences across work specializations related to perception of "teamwork within units" $[F(3,154)=2.84, p=.04]$. Post hoc comparisons using Tukey's LSD test showed that doctors scored significantly higher positive responses $(M=17.5, S D=2.4)$ than paramedical staff $(M=15, S D=$ 2.8). Further, "overall perception of PS" was also significantly different across work specializations $[F(3,154)=$ $5.47, p=.001]$; with doctors scoring higher positive responses $(M=15, S D=3)$ compared to nurses $(M=13, S D=$ 2.5), paramedical staff $(M=13, S D=2)$, and medical assistants $(M=12, S D=2)$. Remaining PS culture composites showed no significant differences across work specializations.

With respect to years of experience at the institution, significant differences were noted only in three dimensions: "teamwork across units" $[F(4,153)=4.86, p=.004]$; "communications openness" $[F(4,153)=2.929, p=.023]$; and "non-punitive response to error" $[F(4,153)=2.85, p=.026]$. Post hoc comparisons using Tukey's LSD test showed that healthcare providers with $\leq 10$ years of experience scored significantly higher positive responses in such dimensions than those with $>10$ years of experience. Significant differences were also noted across "patient contact" characteristic with regards to the dimensions: "communication openness" $[t(156)=3.334, p=.001]$; "non-punitive response to error" $[t(156)=2.153, p=.033]$; "management support for PS" $[t(156)=2.344, p$ $=.02]$; and "supervisor expectation and actions" $[t(156)=2.158, p=.032]$. In such dimensions, participants with direct "patient contact" scored significantly higher than those with less or indirect "patient contact" (Table 4). 
Table 4. Mean Scores of HSPSC Composites by Demographic Characteristic (pt. contact) $(\mathrm{N}=158)$

\begin{tabular}{llllll}
\hline HSPSC Composites & $\begin{array}{l}\text { \% } \\
\text { positive } \\
\text { responses }\end{array}$ & $\begin{array}{l}\text { Direct pt. } \\
\text { contact } \\
\text { Mean (SD) }\end{array}$ & $\begin{array}{l}\text { Indirect pt. } \\
\text { contact } \\
\text { Mean (SD) }\end{array}$ & $\begin{array}{l}\text { No. } \\
\text { items }\end{array}$ & $\begin{array}{l}\text { Max } \\
\text { scores }\end{array}$ \\
\hline Teamwork within dept. & 83 & $16.5(3)$ & $15(2)$ & 4 & 20 \\
Teamwork across dept. & 42 & $14(3)$ & $13(2)$ & 4 & 20 \\
Communication openness* & 53 & $11(2)$ & $9(2)$ & 3 & 15 \\
Feedback about error & 76 & $11.5(2)$ & $11(2)$ & 3 & 15 \\
Frequency of events reported & 34 & $9(3)$ & $9(3)$ & 3 & 15 \\
Organ. learning- cont. improvement & 75 & $12(2.5)$ & $11(2.5)$ & 3 & 15 \\
Non-punitive response to error* & 45 & $8.5(3)$ & $7(2.5)$ & 3 & 15 \\
Management support for PS* & 58 & $10.5(2)$ & $9(2)$ & 3 & 15 \\
Staffing & 51 & $12(3)$ & $13(3)$ & 4 & 20 \\
Supervisor expectations and actions* & 56 & $14(3)$ & $12(2)$ & 4 & 20 \\
Overall perceptions of PS & 47 & $13(3)$ & $12.5(2)$ & 4 & 20
\end{tabular}

${ }^{*} p<=.05$

\section{Discussion}

Patient's safety is a fundamental issue in healthcare organizations. It is a prerequisite for providing quality patient care and accreditation. This study assessed PS culture at the DRCHC in Muscat, Oman; assessed the areas of strength and/or improvement related to PS culture; and assessed the relationship between PS culture and demographic variables. The results suggest that the participants responded positively to the HSPSC items. The average percentage of positive responses was (56.4\%). In light of the fact that PS system in the DRCHC was established recently and is considered in its infancy, these results indicate acceptable and reasonable level of PS culture among the staff of the institution. Such positive findings could also reflect the measures taken by the institution to assure a platform for PS culture such as establishing systems for incidence reporting, policies and procedures, and conducting trainings related to PS. These findings are comparable with research in Oman (Al-Mandhari et al., 2014; Ammouri, Tailakh, Muliira, Geethakrishnan, \& Al Kindi, 2015; Lawati, Short, Abdulhadi, Panchatcharam, \& Dennis, 2019) and elsewhere (Ghobashi, El-Ragehy, Ibrahim, \& Al-Doseri, 2014; Rajalatchumi et al., 2018) but slightly lower than results reported in some studies out of Oman (Chen \& Li, 2010; El-Jardali, Jaafar, Dimassi, Jamal, \& Hamdan, 2010).

At the composites levels, participants reported higher scores in "teamwork within department" dimension (83\%). Participants felt respected and supported by colleagues whenever they needed help. Duties were shared between the staff and most were willing to work together. This could be explained by the fact that most of the units in the DRCHC are small comprising between 10-20 staff. The majority of these staff are from the same culture and meet and interact constantly, which create social and safe work atmosphere. Further, "feedback and communication about errors" was perceived positively (77\%), in which most of the participants felt that they were kept updated about errors happen in the unit and about any consequent changes. The "organizational learning-continuous improvement" dimension also received high scores $(75 \%)$ and considered as the third major strengths for the institution related to PS. Participants reported that they were actively involved in measures to improve PS and continuously assessing the effectiveness of such measures. Significantly, positive staff perception in such dimensions is essential for every healthcare institution to ensure effective and safe care (AHQR, 2020; Berry et al., 2020; IOM, 2004). As mentioned previously, the PS system in the DRCHC is novice, and such findings are promising and could provide direction for further development. Feeling safe in the place of work will help healthcare providers to deliver quality and error-free care (AHQR, 2020; IOM, 2004). Studies (Al-Mandhari et al., 2014; Ammouri, Tailakh, Muliira, Geethakrishnan, \& Al Kindi, 2015; Ghobashi, El-Ragehy, Ibrahim, \& Al-Doseri, 2014) examining this area reported similar findings. However, two of these studies (Al-Mandhari et al., 2014; Ghobashi, El-Ragehy, Ibrahim, \& Al-Doseri, 2014) report less positive scores in "communication and feedback about errors" dimension compared to the current study.

The current study also indicated that the dimensions with the lowest positive scores were "frequency of events 
reported," "teamwork across departments," "non-punitive response to errors" and "overall perception of PS" (34\%, $42 \%, 45 \% \& 47 \%$; respectively). Most of the participants felt challenged when communicating or working with staff from other departments in the institution. Since patient care is an interdisciplinary process, lack of coordination and cooperation between departments undeniably creates mean for an unsafe work environment, subjecting patients to adverse events (JCHO, 2017). Moreover, participants were reluctant to report patients' events because they wanted to avoid blame and consequent punishment. Generally, improvement in the "frequency of events reported" dimension occurs as a result of having positive perception about "non-punitive response to errors." A blame-free work culture in which errors are "treated as an opportunity to improve and not a personal failure" requiring punishment will significantly contribute to PS (Donaldson, Corrigan \& Kohn, 2000) Consequently, in the dimension of "overall perception of PS," participants felt that more attention needs to be paid to prevent errors from happening. To an extent, these findings are in line with many studies (Al-Mandhari et al., 2018; Ammouri, Tailakh, Muliira, Geethakrishnan, \& Al Kindi, 2015; Danielsson, Nilsen, Rutberg, \& Årestedt, 2019; Lawati, Short, Abdulhadi, Panchatcharam, \& Dennis, 2019) predominantly, with the findings about "non-punitive response to error." In these studies, dimensions such as "management support for PS," "communication openness," and "staffing" have also received the least positive scores.

When examining differences in PS levels across the demographics, this study revealed that doctors scored significantly higher in "overall perception of PS" than other healthcare providers; and scored significantly higher in "teamwork within units" compared to paramedical staff. On the same line, participants who reported having direct patient care scored significantly higher positive responses on the overall HSPSC $(p=.05)$. More specifically, they scored higher in "communication openness," "non-punitive response to error," "management support for PS," and "supervisor expectations and actions" dimensions. These results were inconsistent with the findings of (Danielsson, Nilsen, Rutberg \& Årestedt, 2019) who indicated that participants with no or less direct care perceived PS more positively than others with direct patient care. The differences in scores in the current study could be explained in light of the nature of the primary healthcare setting of the DRCHC. While majority of care occurs in primary healthcare setting (Fournier, 2009), most of PS incidences occurring in such settings do not have significant health consequences (Gaal et al., 2011). Correspondingly, participants' roles at the DRCHC including doctors' generally involve in less-invasive interventions, making the occurrence of adverse events unlikely, and thus, creating a sense of safer work-culture among them.

Notably, the current study indicated that participants with fewer years of experience in the institution perceived PS culture more positively, which was inconsistent with other research (Aboul Fotouh, Ismail, Ez Elarab, \& Wassif, 2012; Ammouri, Tailakh, Muliira, Geethakrishnan, \& Al Kindi, 2015). Long work experience, evidently, enhances competency and confidence making it easier for healthcare providers to express opinions on issues related to PS (Danielsson, Nilsen, Rutberg, \& Årestedt, 2019) Such findings call for further investigation. However, positive perception among the participants with fewer years of experience may, presumably, be the result of the PS awareness programs conducted in the institution. Awareness about PS contributes to quality of care and makes healthcare providers in a better position to recognize PS issues and openly discuss them (Danielsson, Nilsen, Rutberg, \& Årestedt, 2019). Anecdotally, most of attendees of these programs were the new healthcare providers in which emphasis was made about establishing a blame-free, non-punitive culture.

The results of this study should be interpreted in light of its limitations. A major limitation of this study is that PS culture was measured by a self-reported instrument in which the accuracy of the reported information is difficult to validate. Some participants may tend to report information in a socially-desirable manner, causing bias in the research findings. Also, while the validity and the reliability of the HSPSC English version were established, further comprehensive study with larger and more diverse samples is required to ensure its psychometric properties in Arab culture.

\section{Conclusion}

Patient safety is an important element in ensuring quality of patient care and accreditation. This study assessed the PS culture among the DRCHC staff using the HSPSC. It sheds lights on the status of PS culture at the institution and highlights areas of strengths and improvements. The findings provide a foundation for further investigations and interventions. The decision makers at the DRCHC may use such results as bases for improvement in PS culture. Programs may be established to improve areas such as "frequency of events reported," "teamwork across departments," and "non-punitive response to errors." Creating a culture that is safe to work is crucial to minimize adverse events and save patients' lives.

\section{Acknowledgment}

The researchers would like to acknowledge Directorate General of Medical Services (DGMS) represented in the 
Director General office and the Department of Planning and Studies for the in-kind support this study has received.

\section{Competing Interests Statement}

The authors declare that there are no competing or potential conflicts of interest.

\section{References}

Aboul Fotouh, A. M., Ismail, N. A., Ez Elarab, H. S., \& Wassif, G. O. (2012). Assessment of patient safety culture among health-care providers at a teaching hospital in Cairo, Egypt. EMHJ-Eastern Mediterranean Health Journal, 18(4), 372-377. https://doi.org/10.26719/2012.18.4.372

Agency for Healthcare Quality and Research (AHQR). (2016). How PSOs help health care organizations improve patient safety culture. Retrieved June, 2020, from https://www.pso.ahrq.gov/sites/default/files/wysiwyg/npsdpatient-safety-culture-brief.pdf

Agency for Healthcare Quality and Research (AHQR). (2019). The History of The Patient Safety Movement. Retrieved February, 2020, from https://psnet.ahrq.gov/primer/patient-safety-101

Al Nadabi, W., Faisal, M., \& Mohammed, M. A. (2020). Patient safety culture in Oman: A national study. Journal of Evaluation in Clinical Practice. 26(5), 1406-1415. PMID: 31749203. https://doi.org/10.1111/jep.13322

Al-Mandhari, A., Al-Zakwani, I., Al-Kindi, M., Tawilah, J., Dorvlo, A. S., \& Al-Adawi, S. (2014). Patient safety culture assessment in Oman. Oman medical journal, 29(4), 264-270. https://doi.org/10.5001/omj.2014.70

Ammouri, A. A., Tailakh, A. K., Muliira, J. K., Geethakrishnan, R., \& Al Kindi, S. N. (2015). Patient safety culture among nurses. International nursing review, 62(1), 102-110. https://doi.org/10.1111/inr.12159

Berry, J. C., Davis, J. T., Bartman, T., Hafer, C. C., Lieb, L. M., Khan, N., \& Brilli, R. J. (2020). Improved safety culture and teamwork climate are associated with decreases in patient harm and hospital mortality across a hospital system. Journal of patient safety, 16(2), pp.130-136. https://doi.org/10.1097/PTS.0000000000000251

Chen, I. C., \& Li, H. H. (2010). Measuring patient safety culture in Taiwan using the Hospital Survey on Patient Safety Culture (HSOPSC). BMC health services research, 10(1), p.152. https://doi.org/10.1186/1472-6963-10-152

Cronbach, L. J. (1951). Coefficient alpha and the internal structure of tests. Psychometrika, 16(3), 297-334. https://doi.org/10.1007/BF02310555

Danielsson, M., Nilsen, P., Rutberg, H., \& Årestedt, K. (2019). A national study of patient safety culture in hospitals in Sweden. Journal of patient safety, 15(4), 328-333.

de Vries., R., Smorenburg, G., \& Boermeester. (2008). The incidence and nature of in-hospital adverse events: a systematic review. BMJ Quality \& Safety. 17(3), 216-23. https://doi.org/10.1136/qshc.2007.023622

Donaldson, M. S., Corrigan, J. M., \& Kohn, L.T. (Eds). (2000). To err is human: building a safer health system (Vol. 6). National Academies Press.

El-Jardali, F., Jaafar, M., Dimassi, H., Jamal, D., \& Hamdan, R. (2010). The current state of patient safety culture in Lebanese hospitals: a study at baseline. International Journal for Quality in Health Care, 22(5), 386-395. https://doi.org/10.1093/intqhe/mzq047

Fournier, A. M. (2009). Primary care remuneration-a simple fix. New England Journal of Medicine, 361(10), 102. https://doi: 10.1056/NEJMopv0907129

Gaal, S., Verstappen, W., Wolters, R., Lankveld, H., van Weel, C., \& Wensing, M. (2011). Prevalence and consequences of patient safety incidents in general practice in the Netherlands: a retrospective medical record review study. Implementation Science, 6(1), 37. https://doi.org/10.1186/1748-5908-6-37

Ghobashi, M. M., El-Ragehy, H. A. G., Ibrahim, H. M., \& Al-Doseri, F. A. (2014). Assessment of patient safety culture in primary health care settings in Kuwait. Epidemiology, Biostatistics and Public Health, 11(3). https://doi.org/10.2427/9101

Institute of Medicine (IOM). (2004). Patient Safety: Achieving a New Standard for Care. The National Academies Press: Washington, DC. https://doi.org/10.17226/10863

Lawati, M. H. A., Short, S. D., Abdulhadi, N. N., Panchatcharam, S. M., \& Dennis, S. (2019). Assessment of patient safety culture in primary health care in Muscat, Oman: a questionnaire-based survey. BMC family practice, 20(1), 50. https://doi.org/10.1186/s12875-019-0937-4 
Ministry of Health (MOH). (2015). Quality and patient safety projects. Retrieved June, 2020, from https://www.moh.gov.om/en/web/directorate-quality-assurance-center/ongoing-projects.

Nieva, V. F., \& Sorra, J. (2003). Safety culture assessment: a tool for improving patient safety in healthcare organizations. BMJ Quality \& Safety, 12(suppl 2), ii17-ii23. https://doi.org/10.1136/qhc.12.suppl_2.ii17

Rajalatchumi, A., Ravikumar, T. S., Muruganandham, K., Thulasingam, M., Selvaraj, K., Reddy, M. M., \& Jayaraman, B. (2018). Perception of patient safety culture among health-care providers in a tertiary care hospital, South India. Journal of natural science, biology, and medicine, 9(1), 14-18. https://doi.org/10.4103/jnsbm.JNSBM_86_17

Slawomirski, L., Auraaen, A., \& Klazinga, N. (2017). The Economics of Patient Safety: Strengthening a value-based approach to reducing patient harm at national level. Retrieved October, 2019, from www.oecd.org/els/health-systems/The-economics-ofpatient-safety-March-2017.pdf

Sorra et al. (2016). Hospital survey on patient safety culture: User guide. Retrieved June, 2020 from http://www.ahrq.gov/qual/ patientsafetyculture/hospcult.pdf.

Sorra, J. S., \& Dyer, N. (2010). Multilevel psychometric properties of the AHRQ hospital survey on patient safety culture. BMC health services research, 10(1), 199. https://doi.org/10.1186/1472-6963-10-199

Raosoft. (2004). Sample size calculator. Retrieved July, 2018 from http://www.raosoft.com/samplesize.html

The Joint Commission of Healthcare Organization. (2017). Patient safety culture. Retrieved June, 2020 from https://jointcommission.new-media-release.com/2017_sea_safety_culture/

Waterson, P., Carman, E. M., Manser, T., \& Hammer, A. (2019). Hospital Survey on Patient Safety Culture (HSPSC): a systematic review of the psychometric properties of 62 international studies. BMJ open, 9(9), p.e026896. https://doi.org/10.1136/bmjopen-2018-026896

World Health Organization (WHO). (2019). Patient Safety - A Grand Challenge for Healthcare Professionals and Policymakers Alike. $\quad$ Retrieved June, 2019 from https://apps.who.int/gb/ebwha/pdf_files/EB144/B144_29-en.pdfs.who.int/iris/handle/10665/118325

\section{Copyrights}

Copyright for this article is retained by the author(s), with first publication rights granted to the journal.

This is an open-access article distributed under the terms and conditions of the Creative Commons Attribution license (http://creativecommons.org/licenses/by/4.0/). 